OPEN ACCESS

Edited by:

Adriano Schimmenti,

Kore University of Enna, Italy

Reviewed by:

Alessandro Musetti,

University of Parma, Italy

Marco Venniro,

National Institute on Drug Abuse

(NIDA), United States

*Correspondence:

Yingzhi Lu

yingzhi.lu.sus@gmail.com

Specialty section:

This article was submitted to

Cognition,

a section of the journal

Frontiers in Psychology

Received: 05 June 2019

Accepted: 05 August 2019

Published: 03 September 2019

Citation:

Wang $K$, Luo J, Zhang T, Ouyang Y, Zhou C and Lu Y (2019)

Effect of Physical Activity on Drug

Craving of Women With Substance Use Disorder in Compulsory Isolation: Mediating Effect of Internal Inhibition.

Front. Psychol. 10:1928.

doi: 10.3389/fpsyg.2019.01928

\section{Effect of Physical Activity on Drug Craving of Women With Substance Use Disorder in Compulsory Isolation: Mediating Effect of Internal Inhibition}

\author{
Kun Wang ${ }^{1}$, Jiong Luo', Tingran Zhang ${ }^{1}$, Yiyi Ouyang ${ }^{1}$, Chenglin Zhou ${ }^{2}$ and Yingzhi Lu ${ }^{2 *}$ \\ ${ }^{1}$ Research Centre for Exercise Detoxification, College of Physical Education, Southwest University, Chongqing, China, \\ 2 School of Kinesiology, Shanghai University of Sport, Shanghai, China
}

Background: Women with substance use disorder has attracted widespread attention as a prominent social issue. According to reports, physical exercise can improve the internal inhibition, effectively reduce the substance user's drug graving, and improve withdrawal symptoms, however, the specific mechanism of internal inhibition should be further considered. This study was designed to determine the critical role of internal inhibition in the path of physical exertion affecting the drug cravings of women drug users.

Methods: By means of Physical Activity Rating Scale (PARS-3), internal Inhibition Scale and Drug Craving Scale, this study investigated the individuals with substance use disorder under rehabilitation in the women compulsory isolation rehabilitation center in Chongqing, China.

Results: (1) Women with traditional drug users had the strongest internal inhibition and new drug use disorder had the highest drug craving. The longer the duration of drug abuse, the lower the internal inhibition and the higher the drug craving. Women with moderate-intensity activity had the strongest internal inhibition and the lowest drug craving. (2) The physical activity intensity was negatively correlated with drug craving, positively correlated with intrinsic inhibition, and negatively correlated with drug craving. (3) Internal inhibition played a partial mediating effect between physical activity intensity and drug craving.

Conclusion: Physical activity has a positive effect on inhibiting drug craving among drug addicts, while moderate-intensity activity seems to be more conducive to enhancing the internal inhibition of addicts, to improving their resistance to drugs, and thus more conducive to reducing drug craving.

Keywords: physical activity, substance use disorder, drug craving, internal inhibition, mediating effect 


\section{INTRODUCTION}

According to the Word Drug Report 2018, about 275 million individuals used drugs at least once in 2016 all over the world, which posing a huge threat to safety and health to humankind. It is well known that when an individual continues to use a certain drug and forms the dependence, it is easy to produce a drug craving and a related drug impulse behavior. Drug craving is the subjective craving of drug addicts or users for drug effects, and their inner expectations of pleasant experience, relieving withdrawal symptoms and negative emotions brought by drugs, and subconsciously paying too much attention to drug-related cues (Washton, 1986; Field et al., 2009). When an individual is craving for drugs, there will be a rift between his real self and his ought self, which will easily lead to negative emotions related to anxiety and depression (De los Cobos et al., 2011). The higher the degree of drug craving, the higher the level of anxiety and depression (Higgins, 1987). On the basis of the self-medication hypothesis, young individuals with high social anxiety may use marijuana to alleviate emotional distress and respond to unpleasant social conditions (Khantzian, 1997), and individuals with higher drug dependence are more likely to be paranoid, and then exacerbate psychotic-like symptoms (Musetti et al., 2016). At the same time, individuals with substance use disorder may actually use substance or excessive behavior as an external regulator and self-medication to treat their emotional disorders and painful mental states, and individuals with alcohol use disorders often suffers more traumatic events in childhood (Craparo et al., 2014; Caretti et al., 2018). Based on this, Schimmenti and Bifulco (2015) pointed out in the report that the Childhood Experience of Care and Abuse (CECA) has good psychometric characteristics and was considered to be the gold standard for assessing trauma and lack of care experienced during childhood, and these also achieved initial results in predicting depression. It can be seen that the psychological mechanism of drug addiction and addictive behavior is very extensive and has always been an important topic in academic circles.

In recent years, the role of physical activity in reducing drug craving has attracted wide attention. Among tobacco abusers, Roberts et al. (2012) found that aerobic activity can significantly reduce tobacco abusers' craving for tobacco, while women tobacco abusers seem to be more likely to abandon tobacco than male tobacco abusers. Linke et al. (2013) pointed out that aerobic activity can effectively prevent or alleviate the negative emotional state when quitting smoking, and reduce their craving for tobacco. Physical activity can reduce the craving for smoking and improve the adverse symptoms after withdrawal. In a study of drug abstainers, such as cannabis and opioids, it was found that after 6 months, three times a week and $2 \mathrm{~h}$ of aerobic activity intervention, drug abstainers' craving for drugs was significantly reduced (Roessler, 2010). Similarly, Buchowski et al. (2011) also found that aerobic exercise can effectively reduce the craving for marijuana by addicts. A review study has shown that the proper physical exercise can effectively inhibit the psychological cravings of the addicts and the corresponding relapse behavior through the regulation of neurotransmitters and hormones (Zhao et al., 2018). Strickland et al. (2016) pointed out that participation in sports can enhance the ability of dopaminergic signaling, especially in the "reward" approach, which can effectively reduce the excessive use of drugs by addicts. Some scholars hypothesized that physical exercise can reduce smoking dependence, and validate the hypothesis through the path model. It have found that among the college students who were addicted to smoking, the greater the amount of physical exercise, the lower the smoking dependence Chang et al. (2014). It can be seen that physical activity does play a positive role in reducing drug craving, but the specific path between these two is still unknown.

Internal inhibition is an important component of executive function of the brain. It intends to cancel a dominant response or stop an inappropriate ability unrelated to action. It is closely related to the prevention and treatment of smoking addiction, hyperactivity disorder, drug abuse and schizophrenia clinically (Schachar et al., 2000; Friedman and Miyake, 2003; Tomporowski et al., 2008). A large number of studies have found that: two consecutive weeks of self-control training can significantly prolong the duration of smoking cessation of the abstainer (Muraven et al., 1999). Individuals with low selfcontrol level are more likely to have drug craving and abuse behavior, while those with high self-control level show less substance abuse behavior (Tarantino et al., 2015). Self-control ability of male drug addicts is one of the important influencing factors of relapse behavior. It is negatively correlated with relapse tendency (Gong et al., 2013). However, this result has not been verified in women with substance use disorder so far. The influence of physical activity on individual inhibition ability is also supported by more studies (Huang et al., 2014). Normal people who participated in aerobic activity performed better in the Flanker tasks related to inhibition, and the frontoparietal network was more optimized in the execution of the task. Low-intensity of acute aerobic activity can promote the performance of the subjects when executing Stroop inhibits task, and effectively improve the activation level of dorsolateral prefrontal cortex and frontal polar brain area (Byun et al., 2014). However, acute aerobic exercise at moderate-intensity is better to promote human inhibition. Empirical studies have shown that both acute exercise and aerobic exercise can improve the inhibitory function of methamphetamine addicts (Buchowski et al., 2011). Although previous studies on the effects of physical exercise on the cravings and physical fitness of women with substance use disorder (see Table 1), whether physical exercise has the same effect on the inhibition ability of women drug users, and the relevant mechanism of action still needs further exploration. As known, acute aerobic activity at moderate-intensity can better promote human inhibition ability, and the response speed of inhibition task after moderate-intensity aerobic activity is significantly better than that of no activity and other activity intensity. Other studies have found that there is an inverted U-shaped relationship between acute aerobic activity and inhibition (Wang and Zhou, 2014).

In conclusion, physical activity plays a unique role in reducing drug users' craving for drugs, improving depression 
TABLE 1 | Research review on physical exercise on the drug craving and physical fitness in women with substance use disorder.

\begin{tabular}{|c|c|c|c|c|}
\hline Authors (Date) & Subjects & Protocol & Frequency & Outcome indicators \\
\hline Dolezal et al., 2013 & $\begin{array}{l}\text { Methamphetamine } \\
\text { dependents (total of } 39 \text { of } \\
\text { men and women aged } \\
\text { 18-55) }\end{array}$ & $\begin{array}{l}\text { Endurance and resistance exercise } \\
\text { (treadmill, smith machine or dumbbell) }\end{array}$ & $\begin{array}{l}3 \text { days/weeks, } \\
1 \mathrm{~h} / \text { times, total of } \\
5 \text { weeks }\end{array}$ & $\begin{array}{l}\text { Significantly increased } \mathrm{Vo}_{2 \max } \text {, leg, and } \\
\text { waist strength and endurance, } \\
\text { significantly decreased fat }\end{array}$ \\
\hline $\begin{array}{l}\text { Rawson et al., } \\
2015\end{array}$ & $\begin{array}{l}\text { Methamphetamine addicts } \\
\text { (total of } 135 \text { of men and } \\
\text { women aged 18-45) }\end{array}$ & $\begin{array}{l}\text { Aerobic exercise and resistance training } \\
\text { (aerobic for } 30 \mathrm{~min} \text {, resistance for } \\
15 \mathrm{~min} \text { ) }\end{array}$ & $\begin{array}{l}3 \text { days/weeks, } \\
55 \text { min/day, total of } \\
8 \text { weeks }\end{array}$ & $\begin{array}{l}\text { Significant improvement in aerobic } \\
\text { performance, heart rate variability, } \\
\text { significantly decreased scores of } \\
\text { depression and anxiety, decreased } \\
\text { relapse rate }\end{array}$ \\
\hline Geng et al., 2016 & $\begin{array}{l}\text { Synthetic drug force (total } \\
\text { of } 60 \text { of women) }\end{array}$ & $\begin{array}{l}\text { Taichi rehabilitation exercise (Wild } \\
\text { horses branching, rewinding, kneeling, } \\
\text { stalking, golden chicken independence } \\
\text { and single whip) }\end{array}$ & $\begin{array}{l}5 \text { days/weeks, } \\
45 \text { min/days, total of } \\
3 \text { months }\end{array}$ & $\begin{array}{l}\text { Significant improvement in systolic } \\
\text { pressure, balance ability, somatization } \\
\text { disorder, depression, and anxiety }\end{array}$ \\
\hline Wang et al., 2017 & $\begin{array}{l}\text { Methamphetamine } \\
\text { dependents (men: } 44 \text {, } \\
\text { women: 6) }\end{array}$ & $\begin{array}{l}\text { Aerobic exercise intervention (cycle } \\
\text { ergometer, jogging, rope skipping) } \\
\text { (warm-up: } 5 \text { min, aerobic exercise: } \\
30 \text { min, cool down: } 5 \text { min) }\end{array}$ & $\begin{array}{l}3 \text { days/weeks, } \\
30-40 \mathrm{~min} / \text { days, total } \\
\text { of } 12 \text { weeks }\end{array}$ & $\begin{array}{l}\text { Effective improvement in physical } \\
\text { fitness, craving degree and emotional } \\
\text { disorder? }\end{array}$ \\
\hline Caretti et al. (2018) & $\begin{array}{l}\text { Clinical group (total } 515 \text { of } \\
\text { women 111, men 398); } \\
\text { Control group (total of } 183 \text {, } \\
\text { women 98, men } 84 \text { ) }\end{array}$ & $\begin{array}{l}\text { the Severity Index (SI); the Seven } \\
\text { Domains Addiction Scale (7DAS) }\end{array}$ & - & $\begin{array}{l}\text { The better psychological assessment } \\
\text { characteristics of The Addictive } \\
\text { Behavior Questionnaire (ABQ) }\end{array}$ \\
\hline Zhang et al., 2018 & $\begin{array}{l}\text { Amphetamine-type } \\
\text { stimulant dependents (men: } \\
\text { 76, women: 79) }\end{array}$ & $\begin{array}{l}\text { Desire for Speed Questionnaire, DSQ; } \\
\text { Sports Activity Rating Scale, PARS-3, } \\
\text { etc. }\end{array}$ & - & $\begin{array}{l}\text { Improving the negative emotions, } \\
\text { mental state, and physical health, and } \\
\text { then alleviate the psychological } \\
\text { cravings of dependents }\end{array}$ \\
\hline Zhu et al., 2018 & $\begin{array}{l}\text { Amphetamine-type } \\
\text { stimulant dependents } \\
\text { (women: 80) }\end{array}$ & $\begin{array}{l}\text { Taichi boxing (warm-up: } 10 \mathrm{~min} \text {, Taichi } \\
\text { for } 40 \text { min, cool-down: } 10 \mathrm{~min} \text { ) }\end{array}$ & $\begin{array}{l}5 \text { days/weeks in first } \\
3 \text { months; } \\
3 \text { days/weeks in } \\
\text { second } 3 \text { months }\end{array}$ & $\begin{array}{l}\text { Increased sleep efficiency, significantly } \\
\text { reduced pulse rate, significantly } \\
\text { improved body fat content, significantly } \\
\text { reduced withdrawal rate }\end{array}$ \\
\hline Nygard et al., 2018 & $\begin{array}{l}\text { Methamphetamine addicts } \\
\text { (men: 17, women: 6) }\end{array}$ & $\begin{array}{l}\text { Resistance training ( } 4 \text { sets of half-squat } \\
\text { exercises) }\end{array}$ & $\begin{array}{l}3 \text { days/weeks, total of } \\
12 \text { weeks }\end{array}$ & Obviously upgrade in physical fitness \\
\hline Liang et al., 2019 & $\begin{array}{l}\text { New drugs (lce, ecstasy, K } \\
\text { powder) abusers (women: } \\
\text { 73) }\end{array}$ & $\begin{array}{l}\text { Yoga and moderate-intensity aerobics } \\
\text { (warm-up: } 10 \mathrm{~min} \text {, aerobics: } 20 \mathrm{~min}, \\
\text { Yoga: } 10 \mathrm{~min} \text { ) }\end{array}$ & $\begin{array}{l}3 \text { days/weeks, } \\
\sim 40 \text { min/days, total of } \\
3 \text { months }\end{array}$ & $\begin{array}{l}\text { Effective alleviated the negative emotion } \\
\text { of depression and anxiety of subjects }\end{array}$ \\
\hline Huang et al., 2019 & $\begin{array}{l}\text { Personnel in drug } \\
\text { rehabilitation center (men: } \\
\text { 7947, women : 790) }\end{array}$ & $\begin{array}{l}\text { Physique measures (cardiopulmonary } \\
\text { fitness, muscular strength fitness, and } \\
\text { neural fitness, etc.) }\end{array}$ & - & $\begin{array}{l}\text { Physical benefits not optimistic, and } \\
\text { significant regional differences }\end{array}$ \\
\hline
\end{tabular}

and anxiety, and increasing drug withdrawal rate. Proper aerobic activity can promote the recovery of the impaired cognitive control ability of drug abusers, enhance the inhibition ability of drug craving, and then achieve the curative effect of rehabilitation. It can be seen that internal inhibition plays a key role between physical activity and drug addicts' craving for drugs. Although most studies have confirmed that physical activity is closely related to internal inhibition, with the change of physical activity intensity, whether internal inhibition will change accordingly has been confirmed by few studies at present. Similarly, few studies have explored physical activity, internal inhibition and drug craving in the path model, especially for women with substance use disorder. Therefore, in view of the limitations of previous studies, this study proposes the following assumptions: (X1) Physical activity was negatively correlated with drug craving. (X2) Internal inhibition was negatively correlated with drug craving. (X3) Physical activity is positively correlated with internal inhibition. (X4) Internal inhibition mediates the physical activity and drug craving of women with substance use disorder (see Figure 1).

\section{SUBJECTS AND METHODS}

\section{Subjects}

All the women with substance use disorder in Chongqing Women's Compulsory Drug Rehabilitation Center during the rehabilitation consolidation period were surveyed.

In order to ensure the validity and reliability of the questionnaire, all the questionnaires of drug users were sent out by the supervisors of the drug rehabilitation center on their behalf. The questionnaires were filled out and collected with the dormitory as a unit, and all the participants signed the informed consent before filling in. A total of 500 questionnaires were sent out and 487 questionnaires were collected, with a collection rate of $97.4 \%$.Twelve invalid questionnaires were excluded, and 465 questionnaires were finally valid, with an 


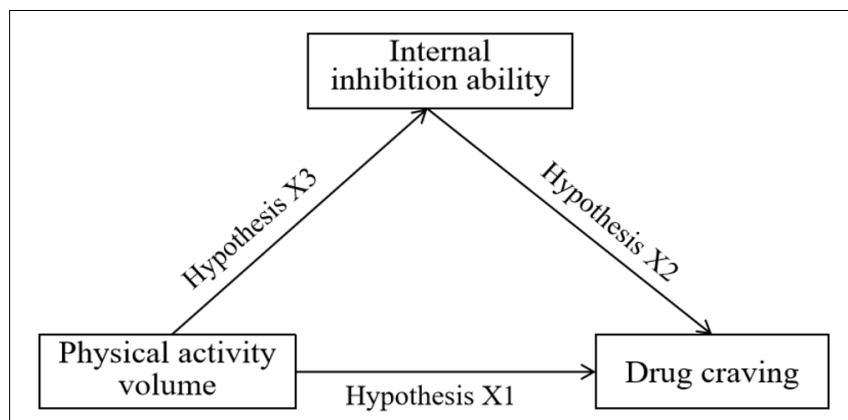

FIGURE 1 | Hypothesis model diagram of mediating effect of internal inhibition ability on physical activity and drug craving.

effective rate of $95.4 \%$. The subjects were $(35.77 \pm 10.29)$ years old, $(1.62 \pm 0.64) \mathrm{m}$ in height, $(57.7 \pm 8.51) \mathrm{kg}$ in weight, (7.76 \pm 7.24$)$ years in drug abuse, 214 in traditional drugs, 119 in new drugs and 132 in mixed drugs (see Table 2).

This study was conducted according to the guidelines laid down in the Declaration of Helsinki and was approved by the ethics committee of Shanghai University of Sport (102772019RT041). Written informed consent form was obtained from all participants before enrolling them in the study.

\section{Research Methods \\ Measures}

Structured questionnaire design was adopted. On the basis of consulting a large number of research literature, through drafting the preliminary draft, predicting the test, analyzing the results of the preliminary test to complete the final draft of the questionnaire, the main contents include three parts consisting of the physical exercise of drug abusers, the internal inhibition, and the current state of medication cravings.

\section{Physical Activity Rating Scale (PARS-3)}

Three-question test method revised by Liang (1994) is adopted, namely the intensity, time and frequency of physical activity, 5-point Likert scale is adopted for quantification, scoring from 1 to 5 points, and thus measure the level of participation in physical activity. Physical activity score = activity intensity score $\times$ (activity time score -1 ) $\times$ activity frequency score, score interval 0 to 100 points. The scale of physical activity is: low intensity physical activity $\leq 19$ points, moderate-intensity physical activity $\leq 20-42$ points, and high intensity physical activity $\leq 43$ points. The predictive test of the questionnaire showed that the test-retest reliability was higher, and the correlation coefficient $r=0.82$.

\section{Internal inhibition scale}

The internal inhibition scale compiled and revised by Jiang and Lin (2000) was adopted. The scale contains 18 items (e.g., I am very easy to lose my temper, or under the teasing of others, I can do almost anything, etc.), which consists of three dimensions. Using 5-point Likert scale to quantify, the choice of "strongly agree, agree, neither agree nor disagree, disagree, strongly disagree" were scored 1-5 points, the higher the score, the stronger the internal inhibition. The internal consistency test showed that the deliberation Cronbach's $\alpha$ coefficient was 0.91 (seven items), the self-control Cronbach's $\alpha$ coefficient was 0.86 (five items), the self-discipline Cronbach's $\alpha$ coefficient

TABLE 2 | Basic characteristics of Subjects.

\begin{tabular}{|c|c|c|c|c|c|}
\hline \multicolumn{2}{|c|}{ Demographic Variable } & \multirow{2}{*}{$\begin{array}{c}\text { Mean } \pm \text { SD/ } \mathbf{n}(\%) \\
35.77 \pm 10.29\end{array}$} & \multicolumn{2}{|c|}{ Drug use-related data } & \multirow{2}{*}{$\begin{array}{c}\text { Mean } \pm \text { SD/ } \mathbf{n}(\%) \\
214(46.02 \%)\end{array}$} \\
\hline Age(years) & & & Drug types & Traditional drug & \\
\hline Body height(m) & & $1.62 \pm 0.64$ & & New drug & $119(25.59 \%)$ \\
\hline Body Weight(kg) & & $57.70 \pm 8.51$ & & Mixed drug & $132(28.39 \%)$ \\
\hline \multirow[t]{4}{*}{ Educational status } & Primary school or below & $107(23.01 \%)$ & Mainly drug used & Cannabis & $60(12.90 \%)$ \\
\hline & Junior & $115(24.73 \%)$ & & Heroin & $95(20.43 \%)$ \\
\hline & Senior & $154(33.12 \%)$ & & Cocaine & 42(9.03\%) \\
\hline & College or above & 89(19.14\%) & & Methomphetamine & $93(2.00 \%)$ \\
\hline \multirow[t]{14}{*}{ Career } & Unemployed & $141(30.32 \%)$ & & K powder & 18(3.87\%) \\
\hline & Self-employed & $135(29.03 \%)$ & & Others & $157(33.76 \%)$ \\
\hline & Staff & 132(28.39\%) & Relapse & Once & $53(11.40 \%)$ \\
\hline & Manual workers & $57(12.26 \%)$ & & Twice & $165(35.48 \%)$ \\
\hline & & & & Three time or more & $247(53.12 \%)$ \\
\hline & & & Drug use years & & $7.76 \pm 7.24$ \\
\hline & & & & $\leq 10$ years & $301(64.7 \%)$ \\
\hline & & & & $>10$ years & $164(35.3 \%)$ \\
\hline & & & Withdrawal period & $\leq 1$ years & $163(35.05 \%)$ \\
\hline & & & & $1-2$ years & 203(43.66\%) \\
\hline & & & & $>2$ years & $99(21.29 \%)$ \\
\hline & & & History of disease & Cardiovascular disease & $85(18.28 \%)$ \\
\hline & & & & Physiological disease & $46(9.89 \%)$ \\
\hline & & & & Mental disorder & $15(3.23 \%)$ \\
\hline
\end{tabular}


was 0.93 (Six items), and the overall Cronbach's $\alpha$ coefficient was 0.952 . The verification results of measurement model are: $\chi^{2} / \mathrm{df}=1.44, \mathrm{RMSEA}=0.03$. AGFI $=0.99, \mathrm{CFI}=0.99, \mathrm{TLI}=0.92$, $\mathrm{IFI}=0.98, \mathrm{GFI}=0.99$. It shows that the questionnaire has good measurement validity and reliability.

\section{Drug craving scale}

The craving belief scale was compiled by Jiang and Lin (2000). The scale contains 22 items (e.g., I can't relieve my anxiety without taking drugs, or the desire for drug use is far better than my willpower, etc.), which consists of three dimensions. Using 5point Likert scale to quantify, the choice of "strongly disagree, disagree, neither disagree nor agree, agree, strongly agree" were scored 1-5 points, the higher the score, the stronger the craving for drugs. Internal consistency test results showed that drug cognition Cronbach's acoefficient was 0.95 (10 items), irrational belief Cronbach $\alpha$ coefficient was 0.94 (seven items),craving degree Cronbach's $\alpha$ coefficient was 0.94 (five items), and overall Cronbach's $\alpha$ coefficient was 0.963 . The validation results of the measurement model are: $\chi^{2} / \mathrm{df}=1.24, \mathrm{RMSEA}=0.03$, AGFI $=0.99$, CFI $=0.99$, TLI $=0.92$, IFI $=0.98$, GFI $=0.99$. It shows that the questionnaire has better measurement validity and reliability.

\section{Statistical Analysis}

Statistical analysis is carried out to the data with SSPS21.0, including variance analysis, correlation analysis, regression analysis, etc.; AMOS21.0 is adopted to construct the model and analyze the path, and the mediation effect is discussed according to Anderson's two-step procedure. The significant level of all indicators was set at $\alpha=0.05$.

\section{RESULTS}

\section{Differences Between the Types and Duration of Drug Abuse on Internal Inhibition and Drug Craving of Women With Substance Use Disorder}

Based on the characteristics of the sample, this study classified the types of drugs used into three types: traditional drugs, new drugs, and mixed drugs. Traditional drugs refer to narcotic drugs that are extracted from natural plants and have sedative and acesodyne effects, which can make person addicted, mainly including opium, heroin, marijuana, etc.; new drugs refer to artificial chemical synthesis such as hallucinogen, stimulants, etc., which can directly act on the central nervous system, produce excitatory or inhibitory effects, irreversible damage to the brain, mainly including methamphetamine, $\mathrm{K}$ powder (mainly ketamine), etc.; mixed drugs refers to the use of the combination of two or more traditional and new drugs for a certain period of time To further explore the effects of years of drug use on internal inhibition and drug craving, the years of drug use were recoded into two categories: (1) 10 years or less (group A); (2) more than 10 years (group B).
Figure 2 shows that the different types and drug use years have significant differences in the internal inhibition and drug craving of women with substance use disorder. In terms of internal inhibition, by within-group comparisons, it has been found that: (1) in the new drug users, there were significant differences in the internal inhibition in women with different drug use years (Group A $>$ Group B, $T=2.01, P<0.05$ ); (2) in the traditional drug users, the internal inhibition of women with different drug use years was significant difference (Group A > Group $\mathrm{B}, T=3.75, P<0.001$ ); (3) in the mixed drug users, there were significant differences in the internal inhibition of women with different drug use years (Group A > Group B, $T=2.42$, $P<0.01$ ) by within-group comparisons, it has been found that in the Group A, significant differences occurred among different types of drug users $(F=5.15, P<0.01$, traditional drug users $>$ new drug users, traditional drug users $>$ mixed drug users), however, there was no significant difference between the new drug users and the mixed drug users $(P>0.05)$, (2) in the Group B, there was no significant difference in the internal inhibition of women with different drug use types $(F=1.18, P>0.05)$.

In terms of drug graving, by within-group comparisons, it has been found that: (1) in new drug users, there were significant differences in drug graving among women with different drug use years (Group A $<$ Group B, $T=-2.52, P<0.01$ ), and (2) in traditional drug users, there were significant differences in drug graving among women with different drug use years (Group A $<$ Group B, $T=-3.96, P<0.001$ ), and (3) in mixed drug users, there was no significant difference in drug craving among women with different drug use years $(T=-0.97, P>0.05)$. By between-group comparisons, the results showed that: (1) there were significant differences in drug craving between traditional drug users and mixed drug users $(F=3.51, P<0.05$, mixed drug users $>$ traditional drug users), but there was no significant difference between new drug users and traditional drug users $(P>0.05)$, new drug users and mixed drug users $(P>0.05),(2)$ there was no significant difference in drug craving among women of different types of drug user $(F=1.00, P>0.05)$.

\section{Differences of Internal Inhibition and Drug Craving of Women With Substance Use Disorder by Physical Activity Intensity}

When processing the data, we found that none of the women with substance use disorder reached the high intensity activity, so only two groups of members were obtained, and the score of low-intensity activity group was $\leq 19$ points; moderate-intensity activity group: $20-42$ points.

In terms of internal inhibition, by within-group comparisons, Figure 3 shows that: (1) when the drug use period was 10 years or less, there were significant differences in the internal inhibition of women with different physical exercise volume (moderate level $>$ low level, $T=-4.42, P<0.001$ ), and (2) when the drug use period was more than 10 years, there was a significant difference in the internal inhibition of women between different exercise volume (moderate exercise 


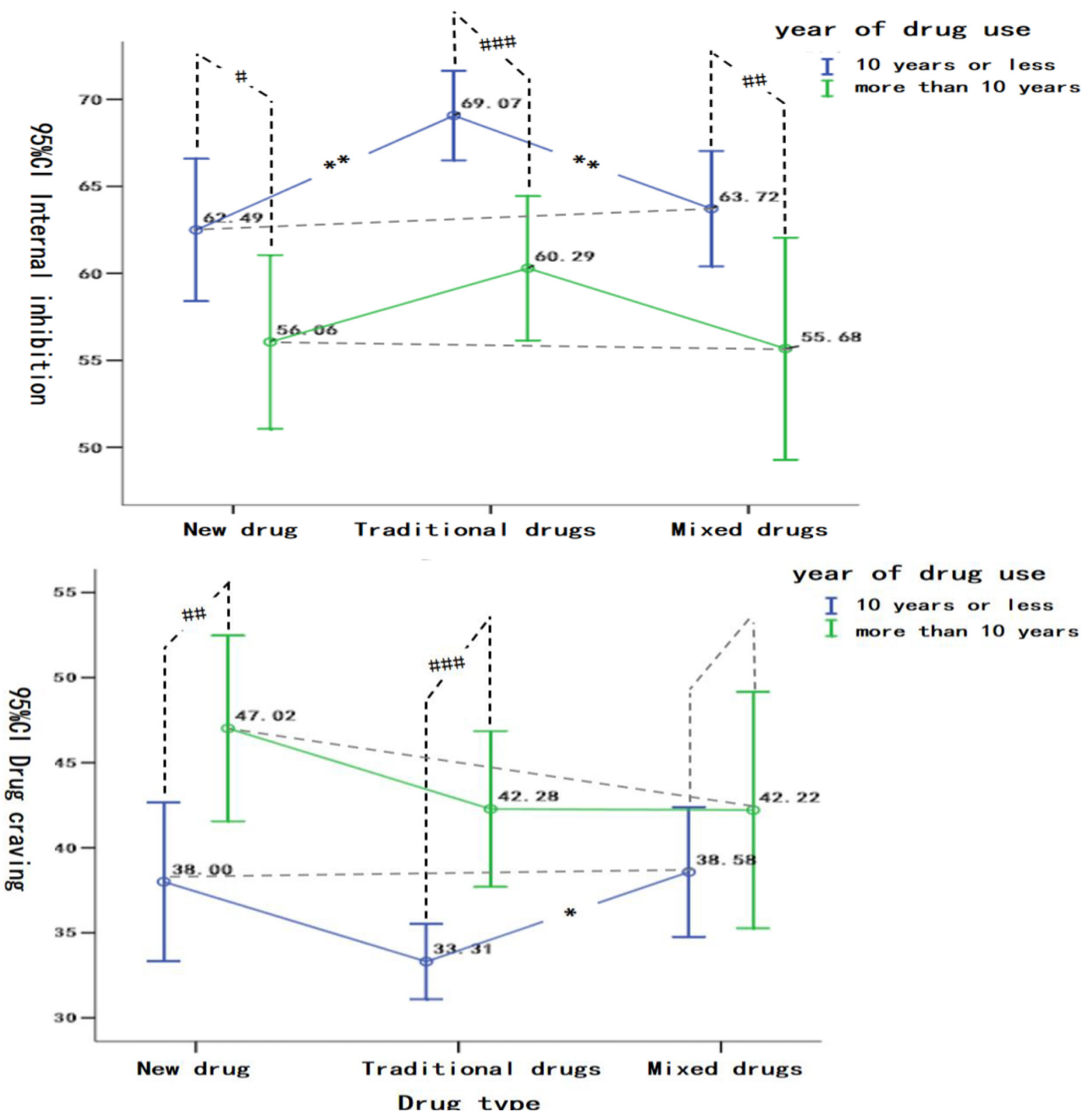

FIGURE 2 | The Differences of the effects of Drug Types and Years in Internal Inhibition and Drug Craving. Within-group comparisons were presented as "\#”, i.e., ${ }^{\#} P<0.05,{ }^{\# \#} P<0.01,{ }^{\# \# \#} P<0.001$; Between-group comparisons were presented as ${ }^{*},{ }^{*} P<0.05,{ }^{* *} P<0.01,{ }^{* * *} P<0.001$.

level $>$ low exercise level, $T=-2.61, P<0.05)$. By betweengroup comparisons, it has been found that: (1) there were significant differences in the internal inhibition of women with different drug use years in low exercise volume (Group A $>$ Group B, $T=3.31, P<0.001$ ), (2) there were significant differences in the internal inhibition of women with different drug use years in moderate exercise volume (Group A < Group B, $T=3.32, P<0.001)$.

In terms of drug craving, by within-group comparisons, it has been showed that: (1) when drug use period was 10 years or less, there were significant differences in drug craving of women with different physical exercise volume (low exercise level $>$ moderate exercise level, $T=3.55, P<0.001$ ), and (2) when drug use period was more than 10 years, there were significant differences in drug craving of women with different physical exercise volume (low exercise level $>$ moderate exercise level, $T=4.48, P<0.001)$. By between-group comparisons, it has been found that: (1) there were significant differences in drug craving of women with different drug use years (Group B $>$ Group A, $T=-3.90, P<0.001)$, (2) there was no significant difference in drug craving of women with moderate exercise volume $(T=-1.21, P>0.05)$. 


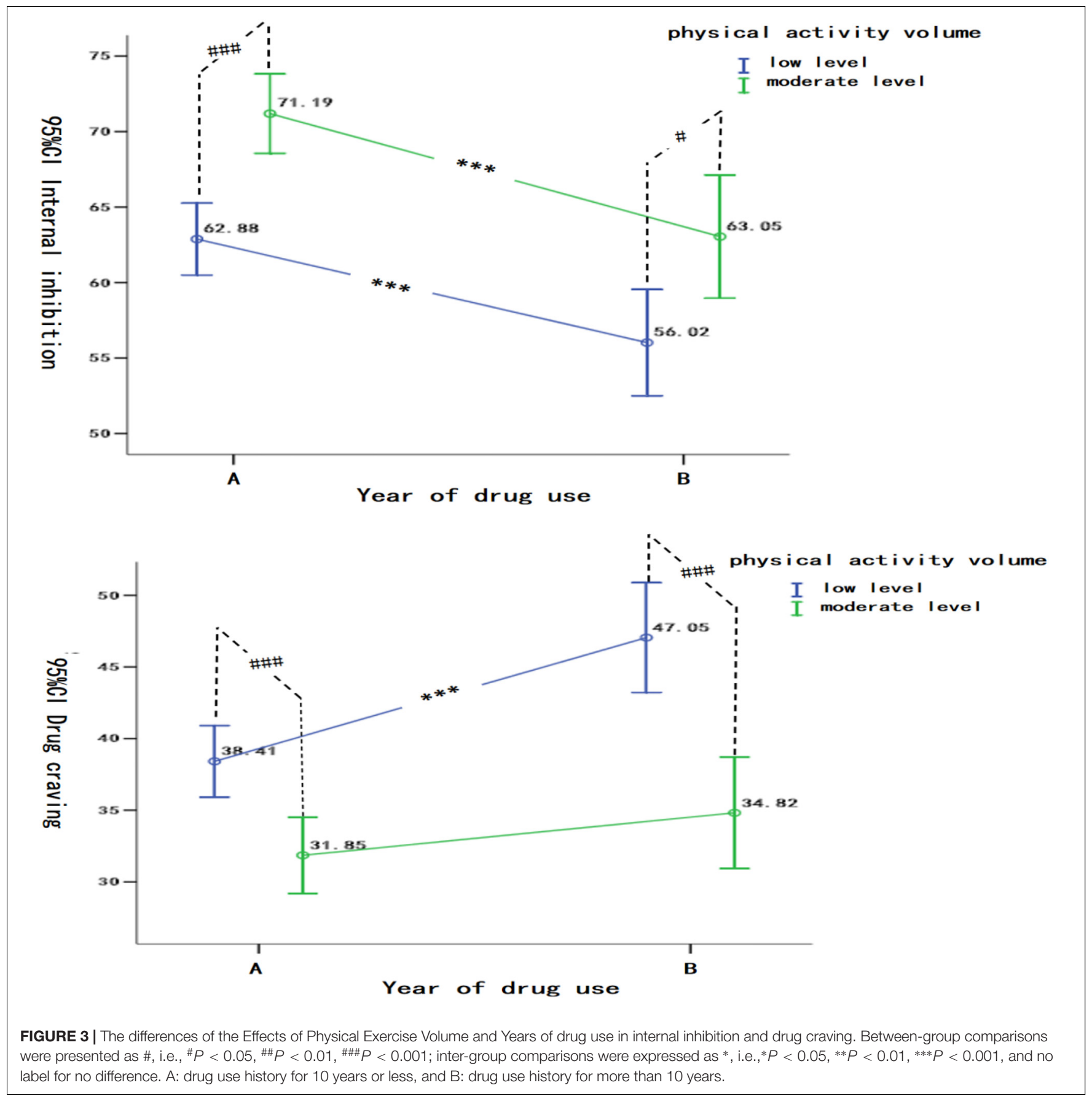

\section{Correlation Among Physical Activity Intensity, Internal Inhibition, and Drug Craving}

Table 3 shows that the physical activity intensity was negatively correlated with drug craving $(r=-0.28)$, the internal inhibition was negatively correlated with drug craving $(r=-0.42)$, and the physical activity intensity was positively correlated with the internal inhibition $(r=0.31)$. The results show that there is a significant correlation among the variables, which provides an ideal footstone for the subsequent test of mediating effect.
Therefore, the hypothesis $\mathrm{X} 1, \mathrm{X} 2$, and $\mathrm{X} 3$ in this study has all been confirmed.

\section{Test of Mediating Effect of Physical Activity Intensity on Drug Craving}

Figure 4 shows: Structural equation model was used to examine the mediating effect of internal inhibition between physical activity and drug craving. The fitting indexes of structural equation model are as follows: $\chi^{2} / \mathrm{df}=1.12$, RMSEA $=0.02$, GFI $=0.99$, TLI $=0.99$, CFI $=0.99$, 
TABLE 3 | Analysis of the correlation among the physical activity intensity, internal inhibition and drug craving $(N=465)$.

\begin{tabular}{|c|c|c|c|c|c|c|c|c|c|}
\hline & $M$ & $S D$ & 1 & 2 & 3 & 4 & 5 & 6 & 7 \\
\hline (2) Internal inhibition & 63.09 & 17.36 & $0.31^{* * *}$ & - & & & & & \\
\hline (4) Drug Cognition & 16.65 & 8.92 & $-0.23^{* * *}$ & $-0.35^{* * *}$ & $0.92^{* * *}$ & - & & & \\
\hline (5) Irrational belief & 14.41 & 7.25 & $-0.25^{* * *}$ & $-0.38^{* * *}$ & $0.87^{* * *}$ & $0.65^{* * *}$ & - & & \\
\hline (6) Craving degree & 7.69 & 4.50 & $-0.28^{* * *}$ & $-0.40^{* * *}$ & $0.83^{* * *}$ & $0.69^{* * *}$ & $0.63^{* * *}$ & - & \\
\hline
\end{tabular}

${ }^{*} P<0.05,{ }^{* *} P<0.01,{ }^{* * *} P<0.001$.

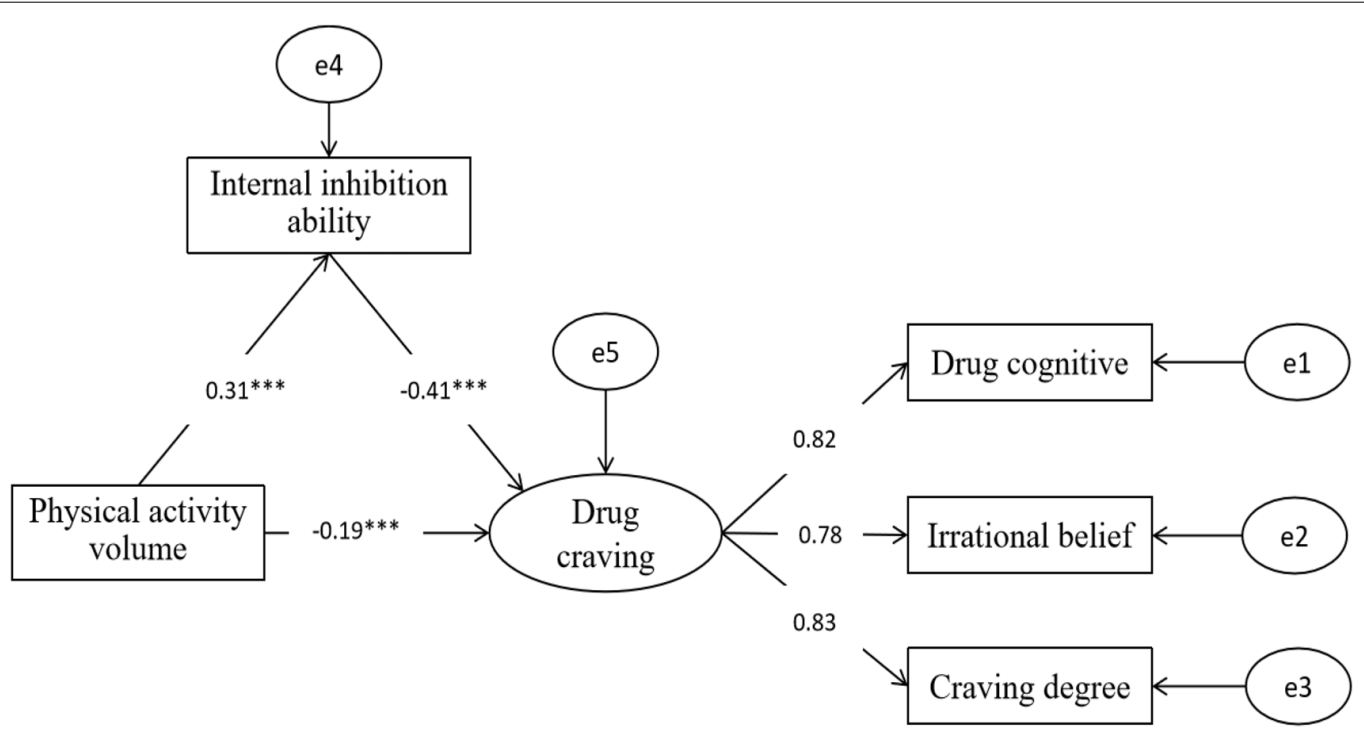

FIGURE 4 | Model diagram of mediating effect of internal inhibition ability on physical activity and drug craving (The digital listed in the figure shows the direct correlation coefficient between variables, it also confirmed the hypothesis in Figure 1).

NFI $=0.99$, AGFI $=0.98$. It indicates that the model fitness is suitable for testing.

Firstly, taking the physical activity intensity as predictive variable and drug craving as dependent variable, the direct effect path coefficient of physical activity intensity on drug craving $(\beta 1=-0.31, P<0.001)$ is significant. Secondly, after adding the internal inhibition between the physical activity intensity and drug craving as the mediating variable, the path coefficients of physical activity and internal inhibition $(\beta=0.31, S E=0.08$, $P<0.001)$ are significant, and the path coefficient of internal inhibition and drug craving $(\beta=-0.41, S E=0.02, P<0.001)$ are significant. It is noteworthy that after adding mediating variable, the path coefficient of physical activity volume and drug craving have been decrease from $(\beta 1=-0.31, P<0.001)$ to $(\beta 2=-0.19, \mathrm{SE}=0.04, P<0.001)$, and the path coefficient remain reached significance, it indicated the partial medicating effect of internal inhibition between physical activity and drug craving, the medicating effect is $(\beta=-0.13, P<0.001)$, so the total ratio of the mediating effect is $41 \%$.Therefore, the hypothesis $\mathrm{X} 4$ of this study has been confirmed.

The path model shows that physical activity can directly and negatively predict drug craving. Internal inhibition can directly and negatively predict drug craving. The physical activity intensity can directly and positively predict the internal inhibition. The physical activity intensity can also produce indirect effect on drug craving through internal inhibition, that is, the greater the physical activity intensity, the stronger the internal inhibition, and then the drug craving can be effectively reduced.

\section{DISCUSSION AND ANALYSIS}

\section{Analysis of the Influencing Factors of Internal Inhibition and Drug Craving}

This study found that the type of drug abuse has a significant impact on internal inhibition and drug craving. Female who uses traditional drugs has higher internal inhibition than those who use new drugs and mixed drugs, which is similar to previous studies (Du and Zhao, 2014). Female who takes new drugs has a higher craving for drugs than those who take traditional drugs. In other words, the use of new drugs has a serious impact on women's internal inhibition, and irreversible damage to the brain of the drug users, and will lead to increased drug craving (Yang, 
2010; Wang T.Y. et al., 2015). Additionally, the duration of drug abuse is another cause for the difference between internal inhibition and drug craving. With the increase of drug addiction years, the degree of brain inhibition function damage increases and the internal inhibition weakens. At the same time, it will increase the craving for drugs, generate the impulse to continue drug abuse, and eventually lead to repeated relapse behavior. Some studies have pointed out that the longer the time of drug abuse, the stronger the drug dependence of drug users (Chen et al., 2017), the stronger the body's tolerance to drugs (Jiang, 2006), the lower the cognitive level, and that female are significantly lower than male (Zhang et al., 2016).

Similarly, the physical activity intensity is another important reason for the difference in the internal inhibition and drug craving among women with substance use disorder. The results of this study show that the total physical activity intensity of women with substance use disorder in Chongqing is at medium or low level. In fact, this special group (women with substance use disorder) restricts their own level of physical activity, so that it is difficult to reach a high level of activity. Women in the moderate-intensity activity group had significantly higher internal inhibition than those in the low-intensity activity group, and their craving for drugs was significantly lower than that in the low-intensity activity group, which was consistent with the earlier studies. For example, the inverted U-shaped theory holds that different intensity of activity has different effects on inhibition ability (Yerkes and Dodson, 1908). Compared with low-intensity and high-intensity aerobic activity, acute aerobic activity at moderate intensity has the greatest promoting effect on human inhibition ability, which can effectively improve cognitive processing efficiency, thereby reducing drug craving and corresponding drug-seeking behavior (Wang T.Y. et al., 2015).

\section{The Direct Influence of Physical Activity on Drug Craving}

The correlation analysis showed that the physical activity intensity was negatively correlated with drug craving of women with substance use disorder. Within a certain range, with the increase of physical activity, it will reduce the drug craving of substance users, which is similar to previous studies (Taylor et al., 2007; Kinnunen et al., 2008; Zhao et al., 2018). Of the college students addicted to smoking, the greater the physical activity intensity, the lower the dependence on smoking (Zhu et al., 2014). Of the MA users, the researchers found that the aerobic activity at moderate intensity for 12 weeks was more effective in reducing drug craving and improving the emotional disorders of the substance users than activity intervention for 6 and 9 weeks (Wang and Zhu, 2017). Specifically, 6 weeks of moderate-intensity activity can reduce drug intake during the initial and maintenance stages of drugs. In abstinence stage, 12 weeks of moderate-intensity activity can significantly reduce drug craving (Friedman and Miyake, 2003). Moderate-intensity activity is most beneficial to the dose-response relationship between drug craving and inhibition control in drug users (Wang D.S. et al., 2015), and can significantly reduce drug craving and drug-seeking behavior in drug users (Sinyor et al., 1982). In the field of neurobiology, there is a similar viewpoint that long-term and sustained moderate-intensity endurance activity can keep the dopamine conversion rate rising steadily, and maintain the dose effect of "increase immediately after activity - decrease slowly after $24 \mathrm{~h}$," thus delaying the relapse interval (Fisher et al., 2004). If the stimulation of physical activity is too large and the time is too long, it will cause metabolic imbalance or metabolic impotence. The synthesis rate of DA far exceeds the metabolic rate, which leads to the "counter-promotion" effect of inducing relapse impulse (Zhao et al., 2018). Therefore, under the condition of controlling the physical activity intensity, the purpose of reducing drug craving can be achieved by increasing the physical activity intensity of drug users, and this study confirms the viewpoint of the above research.

\section{Mediating Effect of Internal Inhibition on Physical Activity and Drug Craving}

Path model shows that physical activity is positively correlated with internal inhibition, while internal inhibition is negatively correlated with drug craving, which is consistent with previous research results (Baumeister et al., 1996; Muraven, 2010; Zhu et al., 2014). With the increase of the physical activity intensity, the internal inhibition of drug-dependent patients will be effectively enhanced, which indicates that physical activity and internal inhibition are mutually reinforcing and influencing, which has also reached a consistent conclusion in the normal population (Roessler, 2010; Barenberg et al., 2011; Drollette et al., 2012). Of course, this does not mean that the higher the physical activity intensity, the better it will be. Especially for drug users, if the physical activity intensity is too large, the relapse impulse will not be effectively suppressed, and even have the opposite side effects (Zhao et al., 2018). Therefore, some studies have pointed out that compared with low-intensity activity, moderateintensity activity can improve the response speed of inhibition task more effectively (Joyce et al., 2009), and acute aerobic activity at moderate intensity can induce the best level of arousal, which has the greatest benefit on cognitive ability (Mcmorris and Hale, 2012). This confirms the findings of this study: between low and moderate-intensity activity, the positive linear relationship between physical activity and internal inhibition is reasonable and scientific, and it also supports and enriches the internal mechanism of inverted U-shaped theory.

In addition, internal inhibition can negatively predict drug craving. Studies have shown that internal inhibition is closely related to drug craving and relapse behavior (Jiang and Lin, 2000; Yang et al., 2007). This has been verified in the study of AIDS drug abusers. There is a significant negative correlation between the internal inhibition of AIDS drug abusers and drug craving (Liu, 2008). That is, the higher the internal inhibition, the lower the drug craving, and the internal inhibition can reduce the occurrence of deviation or criminal behavior. According to the theory of self-control, people with strong self-control ability seldom have bad behaviors, such as smoking, excessive drinking, drug abuse, etc. Through 2 weeks of self-control training, 
smoking addicts can effectively prolong the time to quit smoking (Roessler, 2010). Similarly, some bad behavior can have a negative effect on inhibition function. For example, long-term drug abuse can lead to disorders in the prefrontal area of the brain. Even after withdrawal, the brain function of drug users will be impaired, inhibition and other advanced cognitive functions will still be abnormal (Yuan et al., 2010; Peterson et al., 2014). Therefore, this study establishes a path mechanism between physical activity intensity, internal inhibition and drug craving.

In this study, internal inhibition was used as a mediating variable to explore the relationship between physical activity and drug craving. The results showed that internal inhibition played a part of the mediating role. This shows that physical activity can not only directly reduce drug users' drug craving, but also achieve the rehabilitation benefits of physical detoxification through the mediating effect of internal inhibition. Studies have shown that physical activity can inhibit drug craving by activating the anterior cingulate gyrus and improving cognitive function (Zhao et al., 2017). Although some research theories suggest that high intensity activity can maximize the inhibition ability, and low-intensity acute aerobic activity has a higher accuracy in the inhibition task than moderate-intensity and high intensity (Allard et al., 1989). However, it should be noted that it is very difficult for drug users to achieve high intensity activity, especially among female addicts, which has been fully proved in the practical investigation of this study. For drug users, moderate physical activity intensity plays a significant role in drug craving and drug seeking behavior (Sinyor et al., 1982). When the physical activity intensity is controlled in the moderate-intensity range, with the increase of the physical activity intensity, the internal inhibition will be strengthened, so the resistance to drug and other substances will be stronger, and the more conducive to reducing drug craving. This path mechanism has been supported by many empirical studies in the above studies (Liang, 1994; Peterson and Johnstone, 1995; Yang et al., 2007; Mcmorris and Hale, 2012; Wang and Zhu, 2017). Therefore, through combing the previous studies, this study believes that in the mechanism of activity drug treatment, physical activity should be carried out according to the actual situation, and meanwhile strengthen the monitoring and training of drug users' internal inhibition, and formulate the optimal activity intervention scheme, so as to minimize their drug craving and help them return to their families and society as soon as possible.

\section{CONCLUSION}

(1) Women who take traditional drugs have the strongest internal inhibition, and those who take new drugs have the highest drug craving; the longer the duration of drug abuse, the lower the internal inhibition and the higher the drug craving; women with moderate activity intensity had the strongest internal inhibition and the lowest drug craving.

(2) The physical activity intensity is negatively correlated with drug craving and positively correlated with the internal inhibition, and the internal inhibition is negatively correlated with drug craving.
(3) Internal inhibition plays a partial mediating effect between physical activity intensity and drug craving.

\section{Limitations and Further Research Directions}

This study explores the mediating effect of internal inhibition in the influence of physical activity on women with substance use disorder' drug craving path for the first time. It shows that physical activity can directly or indirectly reduce drug abuser's drug craving in the treatment of drug problem in the whole society. To some extent, it reveals the potential path mechanism of physical detoxification. In the follow-up study, we can further explore the following issues:

(1) Since the cross-sectional study is adopted, we get the correlation among variables, but we cannot get a deeper causal relationship. Longitudinal study can be added to the future study to better reveal the causal relationship among variables.

(2) This study focuses on the mediating variables between internal inhibition and physical activity and drug craving, and more mediating or regulating variables can be explored in the future.

(3) The main research object of this study is the influence of physical activity intensity on drug craving of women with substance use disorder, and male drug users can be added as a comparison in the follow-up study.

\section{DATA AVAILABILITY}

All datasets generated for this study are included in the manuscript and/or supplementary files.

\section{ETHICS STATEMENT}

Human subject research: the studies involving human participants were reviewed and approved by ethics committee of Shanghai University of Sport (102772019RT041). The patients/participants provided their written informed consent to participate in this study.

\section{AUTHOR CONTRIBUTIONS}

All authors designed this study. KW and JL carried out the protocol and questionnaire survey. TZ recruited the individuals with drug addicts. YO and JL undertook the statistical analysis and graphical representation of the data. CZ and YL revised the draft. All authors contributed to and approved the final manuscript.

\section{FUNDING}

This work was supported by the National Social Science Foundation of China (Grant No:17ZDA330). 


\section{REFERENCES}

Allard, F., Brawley, L. R., and Deakin, J. (1989). The effect of exercise on visual attention performance. Hum. Perform 2, 131-145.

Barenberg, J., Berse, T., and Dutke, S. (2011). Executive functional in learning processes: do they benefit from physical activity. Educ. Res. Rev. 6, 208-222. doi: 10.1016/j.edurev.2011.04.002

Baumeister, R. F., Heatherton, T. F., and Tice, D. M. (1996). Losing control: how and why people fail at self-regulation. Contemp. Psychol. 41, 943-944.

Buchowski, M. S., Meade, N. N., Charboneau, E., Park, S., Dietrich, M. S., Cowan, R. L., et al. (2011). Aerobic exercise training reduces cannabis craving and use in non-treatment seeking cannabis-dependent adults. PLoS One 6:e17465. doi: 10.1371/journal.pone.0017465

Byun, K. H., Hyodo, K., Suwabe, K., Ochi, G., Sakairi, Y., Kato, M., et al. (2014). Positive effect of acute mild exercise on executive function via arousal-related prefrontal activations: an fNIRS study. Neuroimage 98, 336-345. doi: 10.1016/j. neuroimage.2014.04.067

Caretti, V., Gori, A., Craparo, G., Giannini, M., Iraci-Sareri, G., and Schimmenti, A. (2018). A new measure for assessing substance-related and addictive disorders: the addictive behavior questionnaire (ABQ). J. Clin. Med. 7:194. doi: 10.3390/ jcm7080194

Chang, Y. K., Chi, L., Etnier, J. L., Wang, C. C., Chu, C. H., and Zhou, C. L. (2014). Effect of acute aerobic exercise on cognitive performance: role of cardiovascular fitness. Psychol. Sport Exerc. 15, 464-470. doi: 10.1016/j.psychsport.2014.04.007

Chen, Y. L., Zhao, M. X., Zhang, J. X., Wang, F. F., Wang, W. X., Zhang, Y., et al. (2017). Analysis of factors related to mental health and drug abuse of drug users in compulsory isolation during rehabilitation. Chinese J. Drug Depend. 26, 465-470. doi: 10.13936/j.cnki.cjdd1992.2017.06.012

Craparo, G., Ardino, V., Gori, A., and Caretti, V. (2014). The relationships between early trauma, dissociation, and alexithymia in alcohol addiction. Psychiatry Invest. 11, 330-335. doi: 10.4306/pi.2014.11.3.330

De los Cobos, J. P., Sinol, N., Trujols, J., Banuls, E., Batlle, F., and Tejero, A. (2011). Drug-dependent inpatients reporting continuous absence of spontaneous drug craving for the main substance throughout detoxification treatment. DrugAlcohol Rev. 30, 403-410. doi: 10.1111/j.1465-3362.2010.00241.x

Dolezal, B. A., Chudzynski, J., Storer, T. W., Abrazado, M., Penate, J., Mooney, L., et al. (2013). Eight weeks of exercise training improves fitness measures in methamphetamine-dependent individuals in residential treatment. J. Addict. Med. 7, 122-128. doi: 10.1097/ADM.0b013e318282475e

Drollette, E. S., Shishido, T., Pontifex, M. B., and Hillman, C. H. (2012). Maintenance of cognitive control during and after walking in preadolescent children. Med. Sci. Sports Exerc. 44, 2017-2024. doi: 10.1249/MSS.0b013e318258bcd5

Du, J., and Zhao, M. (2014). Harm of amphetamine abuse and related intervention measures. Shanghai Med. Pharm. J. 35, 7-9.

Field, M., Munafo, M. R., and Franken, I. H. A. (2009). A meta-analytic investigation of the relationship between attentional bias and subjective craving in substance abuse. Psychol. Bull. 135, 589-607. doi: 10.1037/a001 5843

Fisher, B. E., Petzinger, G. M., Nixon, K., Hogg, E., Bremmer, S., Meshul, C. K., et al. (2004). Exercise-induced behavioral recovery and neuroplasticity in the 1-methyl-4-phenyl-1,2,3,6-tetrahydropyridine-lesioned mouse basal ganglia. J. Neurosci. 77, 378-390. doi: 10.1002/jnr.20162

Friedman, N. P., and Miyake, A. (2003). The relations among inhibition and interference control functions: a latent-variable analysis. J. Exp. Psychol. Gen. 133, 101-135. doi: 10.1037/0096-3445.133.1.101

Geng, J. J., Zhu, D., and Xu, D. (2016). Rehabilitation effect of Taiji rehabilitation exercise on compulsory isolation of female drug abusers. Chin. J. Sports Med. 35, 1048-1051. doi: 10.16038/j.1000-6710.2016.11.011

Gong, B., Zhu, Q., Xiao, X., Luo, H. Z., Tang, S. S., Yang, D. L., et al. (2013). Effect of self-control on relapse tendency of heroin Abstinent. Chinese J. Drug Abuse Prevent. Treat. 19, 311-314.

Higgins, E. T. (1987). SeIf-discrepancy: a theory relating self and affect. Psychol. Rev. 3, 319-340. doi: 10.1037//0033-295x.94.3.319

Huang, C. J., Lin, P. C., Hung, C. L., Chang, Y. K., and Hung, T. M. (2014). ). Type of physical exercise and inhibitory function in older adults: an event-related potential study. Psychol. Sport Exerc. 15, 205-211. doi: 10.1016/j.psychsport. 2013.11.005

Huang, S. B., Bian, Y., Zhu, M. L., Liu, T. T., Lv, H. F., and Ma, L. Z. (2019). Physical health efficiency survey and exercise intervention model building for detoxification addicts under compulsory isolation in guangdong province. China Sport Sci. Technol. 55, 44-55. doi: 10.16470/j.csst.2019041

Jiang, T. (2006). Research on social support network for drug addicts: a survey of drug rehabilitation institutions in Nanan district of Chongqing. Chinese J. Sociol. 4, 160-172. doi: 10.15992/j.cnki.31-1123/c.2006.04.010

Jiang, Z. H., and Lin, R. Q. (2000). A study on the effect of cognitive behavior group therapy on the counseling of drug abusers. J. Criminol. 5, 277-310.

Joyce, J., Graydon, J., Mcmorris, T., and Davranche, K. (2009). The time course effect of moderate intensity exercise on response execution and response inhibition. Brain Cogn. 71, 14-19. doi: 10.1016/j.bandc.2009.03.004

Khantzian, E. J. (1997). The self-medication hypothesis of substance use disorders: a recon-sideration and recent applications. Harv. Rev. Psychiatry 4, 231-244. doi: 10.3109/10673229709030550

Kinnunen, T., Leeman, R. F., Korhonen, T., Quiles, Z. N., Terwal, D. M., Garvey, A. J., et al. (2008). Exercise as an adjunct to nicotine gum in treating tobacco dependence among women. Nicotine Tob. Res. 10, 689-703. doi: 10.1080/ 14622200801979043

Liang, D. Q. (1994). Stress level of college students and its relation with physical exercise. Chinese Ment. Health J. 8, 5-6.

Liang, X. P., Chen, C., Wang, R., and Zhuang, S. M. (2019). Group exercise therapy on quality of life and emotions in female new-type drug addicts. Chin. Gen. Pract. 22, 136-141. doi: 10.3969/j.issn.1007-9572.2018.00.189

Linke, S. E., Ciccolo, J. T., Ussher, M., and Marcus, B. H. (2013). Exercise-based smoking cessation interventions among women. Women's Health 9, 69-84. doi: $10.2217 /$ whe. 12.63

Liu, K. F. (2008). A Study on Drug Desire and Inherent Inhibitory Ability of HIV Inhabitants: A Case Study of Kaohsiung Second Prison, Taiwan, Ministry of Justice. Ho Chi Minh City: Graduate Institute of Regional Policy and Development, NTTU.

Mcmorris, T., and Hale, B. J. (2012). Differential effects of differing intensities of acute exercise on speed and accuracy of cognition: a meta-analytical investigation. Brain Cogn. 80, 338-351. doi: 10.1016/j.bandc.2012.09.001

Muraven, M. (2010). Practicing self-control lowers the risk of smoking lapse. Psychol. Addict. Behav. 24, 446-452. doi: 10.1037/a0018545

Muraven, M., Baumeister, R. F., and Tie, D. M. (1999). Longitudinal improvement of self-regulation through practice: building self-control strength through repeated exercise. J. Soc. Psychol. 139, 446-457. doi: 10.1080/ 00224549909598404

Musetti, A., Terrone, G., Corsano, P., Magnani, B., and Salvatore, S. (2016). Exploring the link among state of mind concerning childhood attachment, attachment in close relationships, parental bonding, and psychopathological symptoms in substance users. Front. psychol. 7:1193. doi: 10.3389/fpsyg.2016. 01193

Nygard, M., Mosti, M. P., Brose, L., Flemmen, G., Stunes, A. K., Sorskar-Venaes, A., et al. (2018). Maximal strength training improves musculoskeletal health in amphetamine users in clinical treatment. Osteoporos. Int. 29, 2289-2298. doi: 10.1007/s00198-018-4623-5

Peterson, A. B., Abel, J. M., and Lynch, W. J. (2014). Dose-dependent effects of wheel running on cocaine-seeking and prefrontal cortex Bdnf exon IV expression in rats. Psychopharmacology 231, 1305-1314. doi: 10.1007/s00213013-3321-4

Peterson, M., and Johnstone, B. M. (1995). The Atwood hall health promotion program, federal-medical-center, Lexington, KY: effects on drug-involved federal offenders. J. Subst. Abuse Treat. 12, 43-48. doi: 10.1016/S0740-5472(99) 80001-4

Rawson, R. A., Chudzynski, J., Mooney, L., Gonzales, R., Ang, A., Dickerson, D., et al. (2015). Impact of an exercise intervention on methamphetamine use outcomes post-residential treatment care. Drug Alcohol Depend. 156, 21-28. doi: 10.1016/j.drugalcdep.2015.08.029

Roberts, V., Maddison, R., Simpson, C., Bullen, C., and Prapavessis, H. (2012). The acute effects of exercise on cigarette cravings, withdrawal symptoms, affect, and smoking behaviour: systematic review update and meta-analysis. Psychopharmacology 222, 1-15. doi: 10.1007/s00213-012-2731-z 
Roessler, K. K. (2010). Exercise treatment for drug abuse-A Danish pilot study. Scand. J. Public Health 38, 664-669. doi: 10.1177/1403494810371249

Schachar, R., Mota, V. L., Logan, G. D., Tannock, R., and Klim, P. (2000). Confirmation of an inhibitory control deficit in attentiondeficit/hyperactivity disorder. J. Abnormal Child Psychol. 28, 227-235. doi: 10.1023/A:1005140103162

Schimmenti, A., and Bifulco, A. (2015). Toward a better understanding of the relationship between childhood trauma and psychiatric disorders: measurement and impact on addictive behaviors. Psychiatry Invest. 12, 415-416. doi: 10.4306/pi.2015.12.3.415

Sinyor, D., Brown, T., and Rostant, P. (1982). The role of a phasical fitness program in the treatment of alcoholism. J. Stud. Alcohol Drugs 43, 380-386. doi: $10.15288 /$ jsa.1982.43.380

Strickland, J. C., Abel, J. M., Lacy, R. T., Beckmann, J. S., Witte, M. A., Lynch, W. J., et al. (2016). The effects of resistance exercise on cocaine selfadministration, muscle hypertrophy, and BDNF expression in the nucleus accumbens. Drug Alcohol Depen. 163, 186-194. doi: 10.1016/j.drugalcdep.2016. 04.019

Tarantino, N., Lamis, D. A., Ballard, E. D., Masuda, A., and Dvorak, R. D. (2015). Parent- child conflict and drug use in college women: a moderated mediation model of self-control and mindfulness. J. Couns. Psychol. 62, 303-313. doi: $10.1037 /$ cou0000013

Taylor, A. H., Ussher, M. H., and Faulkner, G. (2007). The acute effects of exercise on cigarette cravings, withdrawal symptoms, affect and smoking behavior: a systematic review. Addiction 102, 534-543. doi: 10.1111/j.1360-0443.2006. 01739.x

Tomporowski, P. D., Davis, C. L., and Miller, P. H. (2008). Exercise and chidren's intelligence, cognition, and academic achievement. Educ. Psychol. Rev. 20, 111-131. doi: 10.1007/s10648-007-9057-0

Wang, D. S., Zhou, C. L., and Chang, Y. K. (2015). Acute exercise ameliorates craving and inhibitory deficits in methamphetamine: an ERP study. Physiol. Behav. 147, 38-46. doi: 10.1016/j.physbeh.2015.04.008

Wang, D. S., and Zhu, T. (2017). Effects of aerobic exercise on physical fitness, desire and emotional state of methamphetamine dependents. China Sport Sci. 37, 50-59. doi: 10.16469/j.css.201707007

Wang, D. S., Zhu, T., Zhou, C. L., and Chang, Y. K. (2017). Aerobic exercise training ameliorates craving and inhibitory control in methamphetamine dependencies: a randomized controlled trial and event-related potential study. Psychol. Sport Exerc. 30, 82-90. doi: 10.1016/j.psychsport.2017.02.001

Wang, T. Y., Bao, Y. P., Liu, Z. M., Lian, Z., Li, S. X., Sun, S. X., et al. (2015). Symptoms and withdrawal symptoms of amphetamine-type stimulants and K-powder abusers in China. Chinese J. Drug Depend. 24, 377-386. doi: 10. 13936/j.cnki.cjdd1992.2015.05.012

Wang, Y. Y., and Zhou, C. L. (2014). Dose-dependent relationship between intensity of acute aerobic exercise and inhibition ability: evidence from ERP. China Sport Sci. 34, 42-49. doi: 10.16469/j.css.2014.11.001

Washton, M. A. (1986). Relapse prevention: maintenance strategies in the treatment of addictive behaviors. J. Stud. Alcohol 47, 260-261. doi: 10.15288/ jsa.1986.47.260
Yang, B., Liu, X., Yang, S. Y., An, S. S., and Ying, L. H. (2007). The influence of personality, social support and irrational beliefs on drug craving of male drug rehabilitation workers. J. Psychol. Sci. 30, 1413-1417. doi: 10.16719/j.cnki.16716981.2007.06.037

Yang, C. H. (2010). New Drug Addiction is Stronger. Science and Technology Daily. (Version 001). Available at: http://www.stdaily.com/ (accessed May, 2019).

Yerkes, R. M., and Dodson, J. D. (1908). The relation of strength of stimulus to rapidity of habit-formation. J. Comp. Neurol. Psychol. 18, 459-482. doi: 10.1002/ cne.920180503

Yuan, K., Qin, W., Liu, J. X., Guo, Q. A., Dong, M. H., Sun, J. B., et al. (2010). Altered small-world brain functional networks and duration of heroin use in male abstin-ent heroin-dependent individuals. Neurosci. Lett. 477, 37-42. doi: 10.1016/j.neulet.2010.04.032

Zhang, X. H., Xia, Y. W., Wu, G. W., and Lin, Y. Y. (2016). On the influence of Shanghai drug treatment service and social assistance on the effect of drug treatment and correction. Chinese J. Drug Depend. 25, 291-296. doi: 10.13936/ j.cnki.cjdd1992.2016.03.009

Zhang, Z. L., Xu, D., Zhang, M. Z., and Zhu, D. (2018). The relationship between psychological craving and physical and mental health of addicts with amphetamine stimulants. Chin. J. Drug Depend. 27, 129-134. doi: 10.13936/j. cnki.cjdd1992.2018.02.010

Zhao, F. Y., Zhou, C. L., and Liu, T. Z. (2018). Neurobiological mechanism of exercise inhibiting drug addicts' psychological craving and relapse behavior: based on the regulation of exercise on neurotransmitters, hormones and peptides. China Sport Sci. 38, 33-41. doi: 10.16469/j.css.201807016

Zhao, Q., Yang, Q. Q., Deng, Y. Q., and Zhou, C. L. (2017). Research on the effects of physical activity on improving brain function damage in drug addicts withdrawn from drug addiction: evidence from inhibition of processing and resting state of brain function. J. Wuhan Instit. Phys. Educ. 51, 88-94. doi: 10.15930/j.cnki.wtxb.2017.05.015

Zhu, D., Dai, G., Xu, D., Xu, X., Geng, J., Zhu, W., et al. (2018). Long-term effects of tai chi intervention on sleep and mental health of female individuals with dependence on amphetamine-type stimulants. Front. Psychol. 9:1476. doi: 10.3389/fpsyg.2018.01476

Zhu, F. S., Zhou, C. L., and Wang, B. Y. (2014). Physical exercise reduces smoking dependence of College students: mediating role of self-control. Sports Sci. 35, 109-113. doi: 10.13598/j.issn1004-4590.2014.06.020

Conflict of Interest Statement: The authors declare that the research was conducted in the absence of any commercial or financial relationships that could be construed as a potential conflict of interest.

Copyright (c) 2019 Wang, Luo, Zhang, Ouyang, Zhou and Lu. This is an open-access article distributed under the terms of the Creative Commons Attribution License (CC BY). The use, distribution or reproduction in other forums is permitted, provided the original author(s) and the copyright owner(s) are credited and that the original publication in this journal is cited, in accordance with accepted academic practice. No use, distribution or reproduction is permitted which does not comply with these terms. 